\title{
Parental substance use disorder and the risk of adolescent drug abuse: an event history analysis
}

John P. Hoffmann

Brigham Young University - Provo, john_hoffmann@byu.edu

Felicia G. Cerbone

University of Chicago

Follow this and additional works at: https://scholarsarchive.byu.edu/facpub

Part of the Family, Life Course, and Society Commons, and the Medicine and Health Commons

\section{Original Publication Citation}

Hoffmann, John P., and Felicia G. Cerbone. 2002. "Parental Substance Use Disorder and the Risk of Adolescent Drug Abuse: An Event History Analysis." Drug and Alcohol Dependence 66(3): 255-264.

\section{BYU ScholarsArchive Citation}

Hoffmann, John P. and Cerbone, Felicia G., "Parental substance use disorder and the risk of adolescent drug abuse: an event history analysis" (2002). Faculty Publications. 3928.

https://scholarsarchive.byu.edu/facpub/3928 


\title{
Parental substance use disorder and the risk of adolescent drug abuse: an event history analysis ${ }^{2}$
}

\author{
John P. Hoffmann ${ }^{\mathrm{a}, \mathrm{b}, *}$, Felicia G. Cerbone ${ }^{\mathrm{b}}$ \\ ${ }^{a}$ Department of Sociology, Brigham Young University, 844 Spencer W. Kimball Tower, Box 25547, Provo, UT 84602, USA \\ ${ }^{\mathrm{b}}$ National Opinion Research Center, University of Chicago, 1350 Connecticut Avenue, NW, Suite 500, Washington, DC 20036, USA
}

Received 10 July 2001; received in revised form 28 November 2001; accepted 4 December 2001

\begin{abstract}
A common observation in the research literature is that children of drug-dependent parents are at significantly heightened risk of adolescent drug use, abuse, and dependence. Recent research indicates that several psychological and interpersonal factors may affect the association between parents' psychoactive substance use disorder (PSUD) and drug use risks among adolescents, yet studies have failed to examine explicitly whether these factors moderate the association between PSUD and adolescent substance abuse. This paper explores these potential relationships using longitudinal data from a study that has followed three cohorts of adolescents and their families over a 7-year period. The cohorts are defined by parental diagnoses of PSUD, affective disorders, or no diagnosable disorder. The results indicate that PSUD is positively associated with adolescent drug abuse, yet this association is attenuated by strong family cohesion. Affective disorders among parents are associated with a higher risk of alcohol, but not drug, abuse. The associations are stronger in the presence of lower stress and higher self-esteem. PSUD is also associated more strongly with offspring drug and alcohol abuse when levels of use are lower. Hence, some unobserved mechanism that may involve physiological sensitivities to drugs and alcohol appears to put children of parents with drug problems at particular risk of drug and alcohol abuse. Limitations of the data and analysis are discussed. (C) 2002 Elsevier Science Ireland Ltd. All rights reserved.
\end{abstract}

Keywords: Adolescent drug abuse; Parental substance use disorder; Family cohesion; Self-esteem

\section{Introduction}

Research indicates that children of drug-dependent parents experience a heightened risk of adolescent drug use, abuse, and dependence (Luthar et al., 1993; Merikangas et al., 1998; Miles et al., 1998). Although theories of genetic transmission suggest that much of the effect of parents' psychoactive substance use disorder (PSUD) on the risk of adolescent drug problems is relatively unaffected by psychosocial processes (Tsuang et al., 1996; Pickens et al., 1996), recent research

\footnotetext{
An earlier version of the paper was presented at the annual meeting of the American Society of Criminology, San Francisco, CA, November 2000

* Corresponding author. Tel.: +1-801-378-9298; fax: +1-801-3784888.

E-mail address: john_hoffmann@byu.edu (J.P. Hoffmann).
}

indicates that psychosocial factors may affect the association between PSUD and adolescent drug use risks (Chassin et al., 1993; Giancola and Parker, 2001). In particular, several conceptual models suggest that intrapersonal characteristics, family relations, and peer associations either minimize or compound the risks of adolescent drug use (e.g. Dawes et al., 2000). However, few studies have specified whether these factors affect more serious forms of drug use, such as drug dependence or abuse among adolescents. Only a minority of drug users cross the threshold into abuse or dependence, so there remain several questions about the relationships among PSUD, potential moderating factors, and adolescent drug abuse or dependence. The goal of this paper is to explore these relationships using longitudinal data derived from a study that has followed three cohorts of adolescents and their families over a 7-year period. 


\section{Associations among PSUD, moderating factors, and adolescent drug abuse}

PSUD is a key factor in the development of adolescent drug use and abuse. Children living in PSUD families are at high risk of early drug use, drug dependence, and drug abuse. Recent psychopharmacological research suggests that this heightened risk is due largely to physiological characteristics that affect sensitivity to psychoactive substances (Phillips, 1997). Although such research is valuable, it also may lead to a certain complacency among observers who wish to prevent adolescent drug problems. That is, physiological sensitivities often entail invasive physiological solutions.

A more fruitful approach that promises more prevention options is to admit that PSUD may increase the likelihood of adolescent drug and alcohol problems, but to also explore intra- and interpersonal factors that may moderate this relationship. Although there may be physiological factors that affect vulnerability to drug abuse, research should continue to investigate environmental characteristics that affect this vulnerability (McGue et al., 2000). Studies addressing the frequency of adolescent drug use are instructive for this issue. They have shown that intrapersonal characteristics such as self-esteem and interpersonal factors such as family cohesion affect not only drug use (Swadi, 1992; Hoffmann and Su, 1998b; Vega et al., 1993; Kandel, 1990, 1996), but also may affect the relationship between PSUD and drug and alcohol use (Chassin et al., 1993; Hoffmann and $\mathrm{Su}, 1998 \mathrm{a})$. However, few studies have investigated whether these potential moderators are limited to use or also affect more serious forms of drug and alcohol use. The following two sections discuss briefly how intrapersonal and interpersonal characteristics may affect the association between PSUD and adolescent drug and alcohol abuse.

\subsection{Intrapersonal characteristics}

Some research indicates that self-esteem and drug use are not related statistically, yet others have shown a negative association, with higher levels of self-esteem associated with a lower risk of drug use (Hoffmann et al., 2000; Vega et al., 1993). But few studies have investigated the relationship between self-esteem and adolescent drug abuse, or between PSUD and selfesteem. It is likely that, when faced with the environmental turmoil that often accompanies PSUD, youths with low self-esteem have more problems if they begin to use drugs. On the contrary, high self-esteem may provide a buffer to drug abuse problems, even among youths who begin to use drugs.

PSUD is associated not only with adolescent drug use and abuse, but also with depressive symptomatology (Chassin et al., 1991; Hoffmann and Su, 1998b). It is not clear what produces this relationship, but perhaps a tumultuous home environment leads to feelings of sadness and despair, key aspects of depression. Adolescent depression is also related to adolescent drug abuse and dependence (Deykin et al., 1987; Whitmore et al., 1997); hence it is likely that when adolescents are exposed to PSUD and they experience depressive symptoms, the risk of drug and alcohol abuse increases.

\subsection{Interpersonal characteristics}

PSUD families are more likely than other families to experience a variety of stressful life events (Hoffmann et al., 2000; Su et al., 1997). A likely explanation for this association is that these families experience a host of environmental stresses and social disruptions that include such things as poor health, greater economic hardship, and family disruption (Hoffmann and $\mathrm{Su}$, 1998a). Given these experiences, it is not surprising that PSUD is associated with adolescent stress. Moreover, stressful life events increase the risk of adolescent drug use and abuse due to their disruptive influence; drug use is one method by which adolescents cope with hardship (Hoffmann and Su, 1998b; Hoffmann et al., 2000). Given these associations, adolescents who experience a high number of stressful life events and PSUD are more likely than other adolescents to have drug abuse problems.

In a similar manner, PSUD is associated with drugusing peers. The role of peers as a correlate of drug use is well established (Kandel, 1996). Peers provide models and rationalizations for behavior, such as drug or alcohol use (Giancola and Parker, 2001; Swadi, 1992). If adolescents are less engaged with drug-abusing parents, they may be more likely to turn to peers for support and companionship. When these peers use drugs, it is likely that adolescents from these families will also use drugs (Chassin et al., 1993). The question of whether they will also be at higher risk of drug abuse is difficult to answer, though.

Finally, family cohesion has been linked with both PSUD and adolescent drug use and abuse (Farrell et al., 1995). Adolescents who do not feel close to parents are more likely to use drugs and have problems with use (Kandel, 1990, 1996; Stoker and Swadi, 1990). As parents experience PSUD and are disengaged from adolescents, their offspring are likely to be at increased risk of drug abuse.

In sum, research suggests that PSUD is associated with adolescent drug and alcohol use when adolescents experience low self-esteem, more depressive symptoms, more stressful life events, low family cohesion, and associate with drug-using peers. Yet this research has not examined whether these factors affect the risk of alcohol and drug abuse. The goal of this paper is to investigate the association between PSUD and drug and 
alcohol abuse, and explore whether the intra- and interpersonal characteristics described above moderate these relationships.

Moreover, studies have failed to address changes in key characteristics over time. Clearly these characteristics change, especially during adolescence (Hoffmann et al., 2000). Hence, the presumed association between intra- and interpersonal characteristics and drug or alcohol abuse is biased if the dynamic nature of these characteristics is not considered. The following analysis, therefore, uses a dynamic statistical model to consider the direct and moderating effects of these characteristics on the risks of drug and alcohol abuse.

\section{Data and methods}

The data used to examine the relationships are from the Family Health Study (FHS), a prospective study of three cohorts of adolescents. The FHS began in 1991 with more than 800 adolescents aged $10-18$ who resided in the metropolitan area of a large, Midwestern city in the United States. The current analysis is limited to those adolescents aged 11-17 who participated in the screening phase and the seven annual follow-up interviews (about $80 \%$ of these adolescents were aged 11-14 at the screening phase). Details of subject recruitment and diagnostic procedures are provided in a series of previous reports (Hoffmann and Su, 1998a,b; Hoffmann et al., 2000). In brief, parents were recruited from a variety of sources, including mental health clinics, drug treatment facilities, other health clinics, and various communities in the metropolitan area. About $16 \%$ of the total clinic group approached met eligibility criteria (at least one parent resided with at least one youth aged 1013 ), and $85 \%$ of these agreed to participate in the study. Those who refused to participate were slightly more likely to report being single parents, but other demographic characteristics did not distinguish participants from non-participants.

All parents were administered the Structured Clinical Interview for DSM-III-R (SCID) (Spitzer et al., 1990) in late 1991 or early 1992. SCID information was supplemented by the Family Informant Schedule and Criteria (FISC), a tool designed to gather information on family members who were deceased or unwilling to participate ( $6 \%$ of parents had spouses or domestic partners who refused to participate in the study).

The results of the SCID and FISC were used to place families and adolescents into one of three cohorts: PSUD ( $n=243$ adolescents), Affective Disorder $(n=$ 190 adolescents), and a comparison group (no diagnosable mental health disorder; $n=409$ adolescents). A residual group, composed of other diagnoses (primarily psychotic disorder but also other disorders; $n=19$ adolescents), is omitted from the analysis since it represents such a diverse subpopulation. We retained the Affective Disorder group (hereafter AD) since past research indicates that parents' $A D$ is associated with more stress, poorer family relations, and an increased risk of adolescent drug use and abuse (Luthar et al., 1993; Weissman et al., 1997). Parents with dual diagnoses were placed in the PSUD category.

Approximately $95 \%$ of the adolescents who participated in the screening phase and the first year of data collection participated in the study during each of the following six annual data collection efforts. The annual data were collected via self-administered questionnaires that asked about a variety of topics such as family relations, life experiences, and drug use. The final sample used is limited to 804 adolescents who were ages 11-17 during the first year of data collection (mean age $=12.9$ ). This includes 230 adolescents from PSUD families, 186 adolescents from AD families, and 388 adolescents from the comparison families. The sample consists of $51 \%$ females and $49 \%$ males. About $88 \%$ of the sample is white, with small percentages of AfricanAmerican, Hispanic, Asian and Native American youths. The average family income is close to $\$ 40000$ per year, which is similar to the median family income for this area of the USA. Other demographic comparisons with the local population yielded similar results (Hoffmann et al., 2000).

In the final year of data collection all youth participants were administered a computerized version of the Composite International Diagnostic Interview (CIDI) 2.1. The CIDI is a comprehensive fully standardized interview that is designed to assess mental disorders and provide diagnoses according to the definitions of the American Psychiatric Association's Diagnostic and Statistical Manual of Mental Disorders (DSM-IV) (APA, 1994) and the International Classification of Diseases (ICD-10) (WHO, 1992, 1993). The CIDI was developed at the request of the World Health Organization/Alcohol, Drug Abuse and Mental Health Administration (WHO/ADAMA) task force on psychiatric assessment instruments. It is used worldwide and studies indicate that it has good psychometric properties (Andrews and Peters, 1998; Ustun et al., 1997). WHO computer algorithms designed for use with the CIDI were used to produce DSM-IV lifetime diagnoses of drug abuse and alcohol abuse (including exclusion criteria) from the interview responses. DSM-IV criteria for abuse require a maladaptive pattern of substance use with the presence of one or more indicators showing recurrent and significant impairment or distress. Additionally, the person must never have met the criteria for substance dependence. The CIDI diagnosis included reports of age of first occurrence of any symptoms and age of any consequent diagnosis. Therefore, each FHS adolescent respondent was assigned an age of first onset 
of drug or alcohol abuse, if any, based on the CIDI diagnosis.

\subsection{Measures}

The first outcome variable, a CIDI lifetime diagnosis of drug abuse, is a binary variable that is coded zero if the adolescent had not experienced drug abuse problems by the year the data were collected and one if the adolescent had experienced drug abuse problems by the year data were collected. Specifically, a respondent was coded one if he or she met the diagnostic criteria for abuse of one or more of the following drugs: opoids, marijuana, sedatives, cocaine, amphetamines, hallucinogens, inhalants, PCP, and other illicit substances. Drug abuse is defined in the DSM-IV as a maladaptive pattern of drug use demonstrated by one or more recurrent and significant adverse consequence related to the repeated use of drugs. These consequences include failure to fulfill role obligations, use in physically hazardous situations, and legal, social and interpersonal problems (APA, 1994). Unlike the criteria for drug dependence, the criteria for abuse do not include tolerance, withdrawal or a pattern of compulsive use. Given the young age of the respondents, few met the criteria for a lifetime dependence diagnosis at the time of the interview and thus using drug abuse as the outcome variable was deemed more appropriate. Those who were diagnosed with drug dependence were excluded from the final analysis, although research suggests that the pathways to both abuse and dependence are similar (Schuckit and Smith, 2001a).

By the end of the data collection, $91(11.3 \%)$ of the adolescents had experienced problems sufficient to be diagnosed with drug abuse. The second outcome variable, a CIDI diagnosis of alcohol abuse, is coded in a similar manner (74 adolescents $(9.2 \%)$ were diagnosed with alcohol abuse). Interestingly, only nine adolescents had a diagnosis of drug and alcohol abuse; hence, these two groups are relatively independent. Note that both drug abuse and alcohol abuse are time-varying, yet may only occur once in the repeated measures analysis to follow. So, for example, an adolescent may be included in the analysis if she did not have an alcohol abuse problem at ages 12,13 and 14 (corresponding, perhaps, to years $1-3$ of data collection), but is diagnosed with alcohol abuse at age 15 (year 4 of data collection). Thereafter, she is not included in the analysis. The age of onset variable derived by the CIDI scoring program was utilized in determining this cut-off point for those with a positive diagnosis of drug or alcohol abuse. For those respondents who had a diagnosable abuse disorder for more than one drug, the minimum age of onset was used. The average ages of onset for drug and alcohol abuse were 16 and 17 , respectively.
The key explanatory variables, PSUD, AD, and no diagnosable mental disorder, are described above. Since the three groups are represented by three mutually exclusive dummy variables, each coded as zero or one, we specify no diagnosable disorder as the omitted reference group. Hence the coefficients in the statistical model associated with PSUD and AD contrast these adolescents with those from families in which parents are clear of a diagnosable condition.

The other explanatory variables are time-varying covariates that include family cohesion, stressful life events, self-esteem, depressive symptoms, peer drug use, marijuana and other illicit drug use, and alcohol use. The latter two variables are included since drug or alcohol abuse obviously cannot occur unless the adolescent uses drugs or alcohol. Moreover, it is highly likely that more frequent use of these substances over time increases the risk of drug or alcohol abuse (Chen et al., 1997).

Family cohesion is measured with a 16-item scale from FACES-III (Olson et al., 1989). This scale measures family relations as a function of the degree of emotional bonding that family members feel toward one another. The questions comprising the scale ask about family closeness, support, joint activities, and problem solving. Olson et al. (1989) report test-retest correlations of 0.83 and an alpha reliability of 0.87 for this scale. The FHS family cohesion items provide alpha coefficients of 0.90 or higher for each year. The annual scales are based on items that are first standardized within-year and then summed to produce a measure with a grand mean of zero and a standard deviation of 10.14. This corresponds to an unstandardized grand mean of 34.6, with a range of $0-48$.

Stressful life events are assessed each year by a checklist of 18 items derived from the Junior High Life Experiences Survey (Swearingen and Cohen, 1985) and the Family Inventory of Life Events and Life Changes (Olson et al., 1989). The events focus on those that are undesirable and primarily outside the control of the adolescent. They include previous year incidents such as death, illness or accidents among family or friends; changes in school or residence; parental divorce, remarriage, or separation; and family financial problems. Since we are interested in the cumulative effects of stressful life events and since many are likely independent, it is not surprising that the alpha reliabilities are modest (ranging from 0.44 to 0.50 over the 7 years). The minimum number of events during any one year is zero, the maximum is 13 , and the grand mean over the 7 years is 2.1 , with a standard deviation of 1.2 .

Self-esteem is a time-varying covariate that is measured each year by Rosenberg's (1979) scale. The scale includes ten items that assess the respondent's feelings of worth, pride, ability, respect, and satisfaction with life. Higher values indicate higher self-esteem. Each variable 
was standardized within-year prior to creating a summed scale. The unstandardized version of this scale ranges from 0 to 48 , with a grand mean of 35.7 and standard deviation of 6.9. The alpha coefficient for the scale is consistently greater than 0.82 across the 7 years.

Depressive symptoms are measured using the revised Center for Epidemiological Studies Depression Scale (CES-D scale; Radloff, 1977), a 20-item scale designed to assess the frequency of depressive symptomatology in a typical week during the previous 30 days. Adolescent respondents responded on a four-category scale: less than 1 day, 1-2 days, 3-4 days, and 5-7 days. The CES-D is strongly associated with other self-report measures of depressive symptoms (Avison and McAlpine, 1992). Avison and McAlpine (1992) reported an internal reliability (alpha) of 0.90 . The items in the FHS provide an alpha coefficient of more than 0.90 for each year. Each variable was standardized within-year prior to creating a summed scale. The unstandardized version of this scale ranges from 0 to 50 , with a grand mean of 18.5 and a standard deviation of 11.4.

Peer drug use is measured by a set of five questions that ask how many of the adolescents five closest friends have used marijuana, alcohol, or other drugs in the past year, have been high on marijuana or other drugs in the past year, or have been drunk regularly during the past year. Responses to these questions range from none to all. Additive scores are computed after first standardizing each variable within-year. Alpha coefficients for peer drug use range from 0.74 to 0.78 over the 7 years of data collection. Since this variable is highly skewed, the natural logarithm (plus a constant to set its lower bound at one) is used. The grand mean is 1.7 with a standard deviation of 1.2.

Since the models assess both drug abuse and alcohol abuse, two measures of drug use distinguish marijuana and other illicit drug use and alcohol use. The measures are derived primarily from the Monitoring the Future study (Bachman et al., 1997). Marijuana and other illicit drug use is based on a nine-item scale that asks about past-year use of the following substances: marijuana, inhalants, amphetamines, barbiturates, cocaine, crack cocaine, hallucinogens, tranquilizers, and narcotics. The range of responses is from never used (coded 0 ) to 100 or more times (coded 6) for each question. The scale is based on an additive score. Since its distribution is highly skewed, the natural logarithm is used. Alpha coefficients range from 0.68 to 0.82 . The grand mean is 0.37 with a standard deviation of 0.74 .

Alcohol use is based on a set of three questions that ask about the frequency of past-year alcohol use, the frequency of use per occasion (e.g. one drink, two drinks), and how often the adolescent had been drunk in the past year. The scale is computed by summing the responses to the questions. The alpha coefficients for alcohol use range from 0.66 to 0.81 . Like the marijuana/ other drug use scale, alcohol use is highly skewed; hence, its natural logarithm is used in the analysis. The grand mean is 0.75 with a standard deviation is 0.86 .

Finally, we control for age, gender, family income, and race/ethnicity in the analysis. Age is a discrete variable measured at yearly intervals. Its overall range across the 7 years is $11-23$. Gender is coded as 0 for female and 1 for male. Family income is measured on a scale of 1-12 corresponding to increasing monetary levels. Family income is measured during year 1 by the father's report if one is available; otherwise the mother's report is used. When both reports were available, the degree of concordance was high (Pearson's $r=0.88$ ). Its mean of 4.04 corresponds to a family income of about $\$ 40000$ per annum. Race/ethnicity is measured by dummy variable that is coded 0 for non-white and 1 for white. Note that age is the only control variable that is measured as a time-varying covariate; the others are based on data from the first year of interviews.

\subsection{Analytic methods}

There are two characteristics of the model and data that complicate the analysis. The first is that we have "observed" the adolescents in the sample for a limited, though extensive, time period. Although many of the conditions that lead to a diagnosis of drug or alcohol abuse occur during adolescence or early adulthood, some may occur later. Yet we cannot observe these later conditions. In survival analysis terms, this is known as right censoring and leads to biased regression coefficients if it is not considered statistically (Allison, 1995). The second characteristic is that the data are longitudinal, yet the diagnosis of drug or alcohol abuse may occur only once. Although several of the variables are allowed to vary over time within individuals, the outcome variables are binary and may shift from zero to one only once. After a sample member is coded as having a drug or alcohol abuse diagnosis, he or she is dropped from the analysis in subsequent years.

A statistical model that is ideal in this situation is a discrete-time event history model (Allison, 1995). In this model, each individual's "survival" history is separated into a set of distinct time units that are treated as specific observations. In the following analysis, these distinct time units correspond to the seven annual data collection units. The observations are then pooled and the model is usually estimated with a logistic regression model. However, the logistic regression model assumes that events can occur only at discrete time points, even though, in reality, events can occur at any point in time (Allison, 1995). Assuming that the problems sufficient for an abuse diagnosis may occur in continuous time, an alternative regression model substitutes the complementary $\log -\log$ function for the logit function in logistic regression. Using Allison's (1995), p. 216) notation, the 
model is specified as

$\log \left[-\log \left(1-P_{i t}\right)\right]=\alpha_{t}+\beta_{1} x_{i t 1}+\ldots+\beta_{k} x_{i t k}$,

where $P_{i t}$ is the probability of the event for each personyear observed. Note that the explanatory variables, indexed by $x$, include a subscript $t$ that indicates that they vary over time. The complementary $\log -\log$ function allows the outcome variables to take on values of zero or one, but, similar to a continuous random variable, transforms their scale to a quantity that may vary between minus and plus infinity (Allison, 1995). An advantage of using this function is that the coefficients from its regression model may be transformed directly into hazard ratios (relative risk ratios). For example, a coefficient of 0.7 corresponds to a hazard ratio of two. This indicates that the risk of drug abuse among one group, such as males, is two times the risk among some other group, such as females.

The event history models are examined in three stages. The first stage includes only parental diagnosis and the control variables. The second stage adds the key explanatory variables to determine whether the impact of parental diagnosis is attenuated once we consider intra- and interpersonal processes. The final model includes a set of interactions between the explanatory variables and the parental diagnosis indicators. Hence we may determine whether explanatory variables such as family cohesion moderate the impact of PSUD or AD on the risk of drug or alcohol abuse.

\section{Results}

The first issue to address is whether there are any differences in the risk of drug or alcohol abuse by parental diagnosis. Previous studies indicate that children in PSUD families are more likely to suffer from drug and alcohol abuse (Merikangas et al., 1998; Miles et al., 1998). Table 1 provides a preliminary analysis designed to examine this issue. It shows the percentage of adolescents in the FHS who were diagnosed with drug or alcohol abuse by their parents' mental health

Table 1

Percent of adolescents diagnosed with drug abuse or alcohol abuse, by parental diagnosis, Family Health Study, 1992-1998

\begin{tabular}{lll}
\hline Parental diagnosis & Drug abuse & Alcohol abuse \\
\hline PSUD & $18.7^{* *}$ & $11.3 \%^{*}$ \\
Affective disorder & 10.2 & $13.9^{*}$ \\
Clear of diagnosis & 9.0 & 7.0 \\
\hline
\end{tabular}

* Indicates the difference in the percentage between this group and the "clear of diagnosis" group is significant at the $P<0.05$ level (twotailed test) based on Fisher's exact test.

** Indicates the difference in the percentage between this group and the "clear of diagnosis" group is significant at the $P<0.01$ level (twotailed test) based on Fisher's exact test. diagnoses. Fisher's exact test (Kleinbaum et al., 1982) is used to determine whether the group differences are statistically significant.

The results indicate a higher risk of drug abuse among offspring in PSUD families. Compared to adolescents whose parents are clear of a diagnosable disorder, adolescents in PSUD families are more than twice as likely to be diagnosed with drug abuse. The difference between adolescents with AD parents and "clear" parents is not statistically significant, however. Note, however, that PSUD and AD appear to put adolescents at a higher risk of alcohol abuse. It remains uncertain what might be driving these associations, however.

Table 2 provides the three stages of the event history model designed to gauge the risk of drug abuse among FHS participants. The first model supports the results shown in Table 1, even after controlling for the impact of family income, race/ethnicity, gender, and age. Adolescents in PSUD families are more than twice as likely to be diagnosed with drug abuse than adolescents

Table 2

Risk of adolescent drug abuse, Family Health Study, 1992-1998

\begin{tabular}{|c|c|c|c|}
\hline Predictor & Model 1 & Model 2 & Model 3 \\
\hline Intercept & $0.001^{* *}$ & $0.005^{* *}$ & $0.004^{* *}$ \\
\hline $\begin{array}{l}\text { PSUD }^{\mathrm{a}} \\
\text { Affective disorder }^{\mathrm{a}}\end{array}$ & $\begin{array}{l}2.42^{* *} \\
1.28^{*}\end{array}$ & $\begin{array}{l}1.54^{* *} \\
1.09\end{array}$ & $\begin{array}{l}3.70^{* *} \\
1.33\end{array}$ \\
\hline $\begin{array}{l}\text { Family income } \\
\text { White }(1) \text { vs. other ethnic group }(0) \\
\text { Gender (female }=0 ; \text { male }=1) \\
\text { Age }\end{array}$ & $\begin{array}{l}0.88^{* *} \\
2.25^{* *} \\
1.61^{* *} \\
1.19^{* *}\end{array}$ & $\begin{array}{c}0.90^{* *} \\
1.37^{*} \\
1.87^{* *} \\
1.01\end{array}$ & $\begin{array}{c}0.90^{* *} \\
1.46^{*} \\
1.94^{* *} \\
1.01\end{array}$ \\
\hline $\begin{array}{l}\text { Family cohesion } \\
\text { Stressful life events } \\
\text { Self-esteem } \\
\text { Depressive symptoms } \\
\text { Peer drug use } \\
\text { Marijuana and other drug use }\end{array}$ & & $\begin{array}{l}0.99 \\
1.03^{* *} \\
0.95^{* *} \\
0.98^{* *} \\
1.74^{* *} \\
1.93^{* *}\end{array}$ & $\begin{array}{l}1.02^{*} \\
1.04^{*} \\
0.96^{* *} \\
0.98^{* *} \\
1.73^{* *} \\
2.55^{* *}\end{array}$ \\
\hline $\begin{array}{l}\text { Interactions } \\
\text { PSUD*marijuana/other drug use } \\
\text { PSUD*cohesion }\end{array}$ & & & $\begin{array}{l}0.68^{* *} \\
0.98^{*}\end{array}$ \\
\hline $\begin{array}{l}\text { Affective*marijuana/other drug use } \\
\text { Affective*gender } \\
\text { Affective*cohesion } \\
\text { Affective*stress }\end{array}$ & & & $\begin{array}{l}0.65^{* *} \\
2.20^{* *} \\
0.96^{* *} \\
1.08^{* *}\end{array}$ \\
\hline $\begin{array}{l}\text { Dispersion parameter } \\
\text { Deviance } \\
\text { Pseudo- } R^{2}\end{array}$ & $\begin{array}{c}0.91 \\
780.4 \\
0.09\end{array}$ & $\begin{array}{c}0.73 \\
694.6 \\
0.15\end{array}$ & $\begin{array}{c}0.75 \\
685.8 \\
0.17\end{array}$ \\
\hline
\end{tabular}

The coefficients represent relative risk (hazard) ratios. The models are estimated with 7 years of panel data by a generalized linear model with a complementary log-log link function. Age, family cohesion, stressful life events, self-esteem, depressive symptoms, peer drug use, and marijuana/other drug use are measured as time-varying covariates. Only statistically significant interactions are shown in model 3.

a Parents clear of mental health diagnosis is the comparison group.

* Indicates the coefficient differs from one at the $P<0.05$ level (twotailed test).

** Indicates the coefficient differs from one at the $P<0.01$ level (twotailed test). 
from "clear" families. However, note that when we control for the effects of the intra- and interpersonal explanatory variables, this relationship is attenuated substantially. The relationship between AD and drug abuse is attenuated fully by these other variables. More frequent marijuana and other drug use, associating with drug using peers, more stressful life events, fewer depressive symptoms, and lower self-esteem are associated with a higher risk of drug abuse. The negative association involving depressive symptoms is inconsistent with earlier research that has shown a positive association between depression and adolescent drug use (cf. Deykin et al., 1987). However, the fact that the analysis includes parental diagnoses of affective disorders and focuses on drug abuse may explain this finding. Not surprisingly, marijuana/other drug use and peer drug use are strongly associated with the risk of drug abuse (cf. Chen et al., 1997).

Model 3 provides a test of the proposed moderating processes. Note first that many of the main effects remain statistically significant, including PSUD, stress, peer drug use, marijuana/other drug use, self-esteem and depression. However, the interaction terms are the keys to the model. They show that two variables, in particular, moderate the impact of PSUD on adolescent drug abuse: Family cohesion and marijuana/other drug use. The risk ratio of less than one associated with PSUD*cohesion indicates that while PSUD is positively associated with drug abuse on average, its impact is attenuated significantly by higher family cohesion. A similar moderating effect occurs with marijuana/other drug use. PSUD is more strongly associated with drug abuse when marijuana/other drug use occurs less frequently. In other words, adolescents from PSUD families are at higher risk of drug abuse even when they do not use illicit drugs very frequently.

The interactions with AD are similar to those that involve PSUD, although, on average, AD is not significantly associated with drug abuse. In brief, AD is associated with a higher risk of drug abuse when marijuana/other drug use is lower, family attachment is lower, and stressful life events are more frequent. Moreover, AD is more strongly associated with drug abuse among males than among females.

Table 3 provides parallel results with alcohol abuse as the outcome variable. Rather than frequency of marijuana/other drug use, these models include frequency of alcohol use as an explanatory variable. Since alcohol use and marijuana/other drug use are highly related (Pearson's $r=0.65$ ), including both in the model introduced collinearity problems. Moreover, alcohol use should have a more direct impact than marijuana/other drug use on alcohol abuse. PSUD is associated with an increased risk of alcohol abuse in each model, yet so too is AD. These elevated risks persist even after controlling for the effects of several explanatory vari-
Table 3

Risk of adolescent alcohol abuse, Family Health Study, 1992-1998

\begin{tabular}{|c|c|c|c|}
\hline Predictor & Model 1 & Model 2 & Model 3 \\
\hline Intercept & 0.001 & 0.001 & 0.001 \\
\hline $\begin{array}{l}\text { PSUD }^{\mathrm{a}} \\
\text { Affective disorder }^{\mathrm{a}}\end{array}$ & $\begin{array}{l}1.81^{* *} \\
1.83^{* *}\end{array}$ & $\begin{array}{l}1.40^{* *} \\
1.68^{* *}\end{array}$ & $\begin{array}{r}11.59^{* *} \\
4.27^{* *}\end{array}$ \\
\hline $\begin{array}{l}\text { Family income } \\
\text { White }(1) \text { vs. other ethnic group }(0) \\
\text { Gender }(\text { female }=0 ; \text { male }=1) \\
\text { Age }\end{array}$ & $\begin{array}{l}0.99 \\
1.30 \\
1.40^{* *} \\
1.18^{* *}\end{array}$ & $\begin{array}{l}1.03 \\
0.97 \\
1.69^{* *} \\
1.06^{*}\end{array}$ & $\begin{array}{l}1.02 \\
1.05 \\
1.86^{* *} \\
1.07^{*}\end{array}$ \\
\hline $\begin{array}{l}\text { Family cohesion } \\
\text { Stressful life events } \\
\text { Self-esteem } \\
\text { Depressive symptoms } \\
\text { Peer drug use } \\
\text { Alcohol use }\end{array}$ & & $\begin{array}{l}1.00 \\
1.01 \\
0.94^{* *} \\
0.99 \\
1.72^{* *} \\
1.41^{* *}\end{array}$ & $\begin{array}{l}0.99 \\
1.00 \\
0.92^{* *} \\
1.00 \\
2.70^{* *} \\
1.46^{* *}\end{array}$ \\
\hline $\begin{array}{l}\text { Interactions } \\
\text { PSUD*alcohol use } \\
\text { PSUD*gender } \\
\text { PSUD*self-esteem } \\
\text { PSUD*peer drug use }\end{array}$ & & & $\begin{array}{l}0.91^{* *} \\
0.66^{*} \\
1.04^{*} \\
0.40^{* *}\end{array}$ \\
\hline $\begin{array}{l}\text { Affective*alcohol use } \\
\text { Affective*cohesion } \\
\text { Affective*self-esteem } \\
\text { Affective*stress } \\
\text { Affective*peer drug use }\end{array}$ & & & $\begin{array}{l}0.97^{*} \\
1.04^{* *} \\
1.03^{*} \\
0.88^{* *} \\
0.65^{* *}\end{array}$ \\
\hline $\begin{array}{l}\text { Dispersion parameter } \\
\text { Deviance } \\
\text { Pseudo- } R^{2}\end{array}$ & $\begin{array}{c}0.94 \\
749.7 \\
0.05\end{array}$ & $\begin{array}{c}0.94 \\
684.8 \\
0.13\end{array}$ & $\begin{array}{c}0.98 \\
667.1 \\
0.15\end{array}$ \\
\hline
\end{tabular}

The coefficients represent relative risk (hazard) ratios. The models are estimated with 7 years of panel data by a generalized linear model with a complementary $\log -\log$ link function. Age, family cohesion, stressful life events, self-esteem, depressive symptoms, peer drug use, and marijuana/other drug use are measured as time-varying covariates. Only statistically significant interactions are shown in model 3.

a Parents clear of mental health diagnosis is the comparison group.

* Indicates the coefficient differs from one at the $P<0.05$ level (twotailed test).

** Indicates the coefficient differs from one at the $P<0.01$ level (twotailed test).

ables. Moreover, the results of Model 3 show that PSUD and alcohol abuse are associated more strongly at less frequent levels of alcohol use. They are also more strongly associated at lower levels of peer drug use. AD is more strongly associated with alcohol abuse when stressful life events are high. Family cohesion does not attenuate the risk of alcohol abuse among the PSUD group, but it does serve this function among the AD group.

Finally, self-esteem has an interesting effect on the relationships among PSUD, AD, and the risk of alcohol abuse. The association between PSUD and alcohol abuse and between AD and alcohol abuse is stronger when self-esteem is high than when self-esteem is high. It appears that self-esteem fails to buffer the negative effects of PSUD and AD. 


\section{Discussion}

Numerous studies indicate that drug problems among parents increase the risk of drug and alcohol problems among children (e.g. Merikangas et al., 1998; Miles et al., 1998). Yet the associations between parental drug problems and offspring drug and alcohol abuse are not immutable. It is therefore important that research explores the processes by which parental drug problems affect potential offspring drug problems. The present analysis offers an initial exploration of some of these processes by considering several factors that may attenuate or magnify the relationship between PSUD and adolescent drug and alcohol abuse.

The analysis shows that intra- and interpersonal characteristics such as family cohesion, stressful life events, self-esteem, and depressive symptoms affect the relationship between PSUD and adolescent drug abuse (cf. Chassin et al., 1993; Hoffmann and Su, 1998a). One important moderating effect involves family cohesion. When family cohesion is weak, the risk of drug abuse in PSUD families is much greater than when family cohesion is strong. Supporting literature that indicates that strong family relationships attenuate the impact of disadvantaged family circumstances (Farrell et al., 1995; Su et al., 1997), we find that this effect serves to diminish the impact of PSUD on adolescent drug abuse. It is unclear why this buffering effect does not extend to alcohol abuse. Perhaps the more common (and licit) nature of alcohol in American society makes family cohesion a less important determinant of problematic alcohol use.

Another important finding involves the impact of drug and alcohol use on the relationships among PSUD, $\mathrm{AD}$, and drug and alcohol abuse. While it is not surprising that drug and alcohol abuse are more likely as drug and alcohol use increase (cf. Chen et al., 1997), it is intriguing to find that PSUD and AD are more strongly associated with drug and alcohol abuse at lower levels of use. Among adolescents who use drugs or alcohol less frequently, those from PSUD and AD families are at a higher risk of abuse than adolescents whose parents do not suffer from a diagnosable mental disorder. A similar process affects the relationship between PSUD, AD, peer drug use, and alcohol abuse, with a higher risk of alcohol abuse at lower levels of peer drug use.

This result appears to be inconsistent with clinical studies that indicate that those diagnosed with drug dependence are less sensitive to the effects of drugs and alcohol (Schuckit and Smith, 2001b). But these studies are primarily retrospective since they test the sensitivity of those who are already diagnosed with dependence and abuse. The present study is prospective and suggests that there is a level of use that may more easily transform into abuse for adolescents from PSUD families. Moreover, it is tempting to link this finding with genetic research that has supported intergenerational transmission models of drug and alcohol abuse. If a genetic component explains differential sensitivity to psychoactive substances (Phillips, 1997), and it is this sensitivity that partially explains abuse and dependence, then many adolescents may have acquired from their parents a physiological predisposition to problem use that requires less frequent use of these substances to be realized.

Interpreting the results in this way is complicated by the fact that both PSUD and AD interact with drug and alcohol use in a similar manner. Although there may be an intricate genetic relationship that affects vulnerability resulting from affective and substance use disorders, more research is needed to investigate such relationships. Nevertheless, a key lesson that should be derived from this analysis is that children in PSUD and AD families should be particularly careful should they decide to indulge in alcohol or drug use.

Finally, it is important to note that the relationship between PSUD and drug abuse remains statistically significant even after controlling for a host of explanatory variables. Hence there may be other physiological or psychosocial factors that influence familial transmission of drug problems. However, the relationship between AD and drug abuse diminishes to non-significance in the models that include other explanatory variables. Yet, $\mathrm{AD}$ continues to be associated with alcohol abuse. These variable results involving PSUD and $\mathrm{AD}$ offspring suggest that different mechanisms are involved in the relationships among PSUD, AD, drug abuse, and alcohol abuse (Luthar et al., 1993). Nevertheless, alcohol abuse is much more widespread than drug abuse in the USA, especially in adulthood, and affective disorders are more common than psychoactive substance use disorders (US Department of Health and Human Services, 1999). Hence it is important that the factors that link parental AD and alcohol problems be explored in more detail (see Weissman et al., 1997; Luthar et al., 1993), especially since those who treat affective disorders in families may not be sensitive to the myriad behavioral risks to children in these families.

Although compelling, the results of this study must be viewed cautiously because of data limitations. First, although research indicates that the CIDI has good psychometric properties (Andrews and Peters, 1998) it still may suffer from many of the same problems as other self-report instruments (e.g. memory decay). Hence age at initial diagnosis may be biased. Moreover, the measurement of family cohesion, drug using peers, and other variables are based only on adolescent reports; independent verification of these variables from peers, parents, or other associates is not available. Second, parental diagnoses are not as finely detailed as one might prefer. In categorizing families, preference 
was given to PSUD, so that some families may have included dual diagnoses of one or both parents (cf. Dierker et al., 1999; Luthar et al., 1993). Similarly, although the youth diagnoses were distinguished by drug or alcohol abuse, the parental diagnoses were not so finely distinguished. More parents in the PSUD group had primarily alcohol problems than drug problems (although some had both), yet the data do not allow a detailed analysis of PSUD by alcohol versus drug problems, or by dual diagnoses. Finally, the study is limited to drug abuse only, even though PSUD and $\mathrm{AD}$ are likely to also affect other externalizing behaviors such as aggression (Weissman et al., 1997).

\section{Acknowledgements}

This research was funded by grant number DA05617 from the National Institute on Drug Abuse, Dean R. Gerstein, Principal Investigator. We would like to thank the anonymous reviewers for helpful comments and suggestions.

\section{References}

Allison, P.D. 1995. Survival Analysis Using the SAS System: A Practical Guide. SAS Institute, Cary, NC.

American Psychiatric Association (APA), 1994. Diagnostic and Statistical Manual of Mental Disorders, fourth ed. American Psychiatric Association, Washington, DC.

Andrews, G., Peters, L. 1998. The psychometric properties of the Composite International Diagnostic Interview. Soc. Psychiatry Psychiatr. Epidemiol. 33, 80-88.

Avison, W.R., McAlpine, D.D. 1992. Gender differences in symptoms of depression among adolescents. J. Health Soc. Behav. 33, 77-96.

Bachman, J.G., Wadsworth, K.N., O'Malley, P.M., Johnston, L.D., Schulenberg, J.E. 1997. Smoking, Drinking, and Drug Use in Young Adulthood. Lawrence Erlbaum, Mahwah, NJ.

Chassin, L., Pillow, F., Curran, P., Molina, B.S., Barrera, M. 1993. Relation of parental alcoholism to early adolescent substance use: A test of three mediating mechanisms. J. Abnorm. Psychol. 102, 3 19.

Chassin, L., Rogosch, F., Barrera, M. 1991. Substance use and symptomatology among adolescent children of alcoholics. J. Abnorm. Psychol. 100, 449-463.

Chen, K., Kandel, D.B., Davies, M. 1997. Relationships between frequency and quantity of marijuana use and last year proxy dependence among adolescents and adults in the United States. Drug Alcohol Depend. 46, 53-67.

Dawes, M.A., Antelman, S., Vanyukov, M.M., Giancola, P., Tarter, R.E., Susman, E.J., Mezzich, A., Clark, D. 2000. Developmental sources of variation in liability to adolescent substance use disorders. Drug Alcohol Depend. 61, 3-14.

Deykin, E.Y., Levy, J.C., Wells, V. 1987. Adolescent depression, alcohol and drug abuse. Am. J. Publ. Health 77, 178-182.

Dierker, L.C., Merikangas, K.R., Szatmari, P. 1999. Influence of parental concordance for psychiatric disorders on psychopathology in offspring. J. Am. Ac. Child Adolesc. Psychiatry 38, 280-288.

Farrell, M.P., Barnes, G.M., Barerjee, S. 1995. Family cohesion as a buffer against the effects of problem-drinking fathers on psycho- logical distress, deviant behavior, and heavy drinking in adolescents. J. Health Social Behav. 36, 377-385.

Giancola, P.R., Parker, A.M. 2001. A six-year prospective study of pathways toward drug use in adolescent boys with and without a family history of a substance use disorder. J. Studies Alcohol 62, $166-178$.

Hoffmann, J.P., Cerbone, F.G., Su, S.S. 2000. A growth curve analysis of cumulative stress and adolescent drug use. Subst. Use Misuse 35, $687-716$

Hoffmann, J.P., Su, S.S. 1998a. Parental substance use disorder, mediating variables and adolescent drug use: A non-recursive model. Addiction 93, 1351-1364.

Hoffmann, J.P., Su, S.S. 1998b. Stressful life events and adolescent substance use and depression: Conditional and gender differentiated effects. Subst. Use Misuse 33, 2219-2262.

Kandel, D.B. 1990. Parenting styles, drug use, and children's adjustment in families of young adults. J. Marriage Family 52, 183-196.

Kandel, D.B. 1996. The parental and peer contexts of adolescent deviance: An algebra of interpersonal influences. J. Drug Issues 26, 289-315.

Kleinbaum, D.G., Kupper, L.L., Morgenstern, H. 1982. Epidemiologic Research: Principles and Quantitative Methods. Van Nostrand Reinhold, New York.

Luthar, S.S., Merikangas, K.R., Rounsaville, B.J. 1993. Parental psychopathology and disorders in offspring: A study of relatives of drug abusers. J. Nerv. Ment. Dis. 181, 351-357.

McGue, M., Elkins, I., Iacono, W.G. 2000. Genetic and environmental influences on adolescent substance use and abuse. Am. J. Med. Genet. 96, 671-677.

Merikangas, K.R., Stolar, M., Stevens, D.E., Goulet, J., Preisig, M.A., Fenton, B., Zhang, H., O'Malley, S.S., Rounsaville, B.J. 1998. Familial transmission of substance use disorders. Arch. Gen. Psychiatry 55, 973-979.

Miles, D.R., Stallings, M.C., Young, S.E., Hewitt, J.K., Crowley, T.J., Fulker, D.W. 1998. A family history and direct interview study of familial aggregation of substance abuse: The adolescent substance abuse study. Drug Alcohol Depend. 49, 105-114.

Olson, D.H., McCubbin, H.I., Barnes, H.L., Larsen, A.S., Muxen, M.J., Wilson, M.A. 1989. Families: What Makes Them Work. Sage, Newbury Park, CA.

Phillips, T.J. 1997. Behavioral genetics of drug sensitization. Crit. Rev. Neurobiol. 11, 21-33.

Pickens, R.W., Elmer, G.I., LaBuda, M.C., Uhl, G.R. 1996. Genetic Vulnerability to Substance Abuse. Springer-Verlag, Berlin, Germany.

Radloff, L.S. 1977. The CES-D scale: A self-report depression scale for research in the general population. App. Psychol. Meas. 1, 385401.

Rosenberg, M. 1979. Conceiving the Self. Basic Books, New York

Schuckit, M.A., Smith, T.L. 2001a. A comparison of correlates of DSM-IV alcohol abuse or dependence among more than 400 sons of alcoholics and controls. Alcohol Clin. Exp. Res. 25, 1-8.

Schuckit, M.A., Smith, T.L. 2001b. The clinical course of alcohol dependence associated with a low level of response to alcohol. Addiction 96, 903-910.

Spitzer, R.L., Williams, J.B.W., Gibbon, M., First, M.B., 1990. Structural Clinical Interview for DSM-III-R_Patient Edition, Version 1.0. American Psychiatric Press, Washington, DC.

Stoker, A., Swadi, H. 1990. Perceived family relationships in drug abusing adolescents. Drug Alcohol Depend. 25, 293-297.

Su, S.S., Hoffmann, J.P., Johnson, R.A., Gerstein, D.R. 1997. The effect of home environment on adolescent substance use and depressive symptoms. J. Drug Issues 27, 851-877.

Swadi, H. 1992. Relative risk factors in detecting adolescent drug abuse. Drug Alcohol Depend. 29, 253-254. 
Swearingen, E.M., Cohen, L.H. 1985. Measurement of adolescent's life events: The junior high life experiences survey. Am. J. Comm. Psychol. 13, 69-85.

Tsuang, M.T., Lyons, M.J., Eisen, S.A., Goldberg, J., True, W., Lin, N., Meyer, J.M., Toomey, R., Faraone, S.V., Eaves, L. 1996. Genetic influences on DSM-III-R drug abuse and dependence: A study of 3,372 twin pairs. Am. J. Med. Genet. 67, 473-477.

US Department of Health and Human Services, 1999. Mental Health: A Report of the Surgeon General. Author, Rockville, MD.

Ustun, B., Compton, W., Mager, D., Babor, T., Baiyewu, O., Chatterji, S., Cottler, L., Gogus, A., Mavreas, V., Peters, L., Pull, C., Saunders, J., Smeets, R., Stipec, M.R., Vrasti, R., Hasin, D., Room, R., Van den Brink, W., Regier, D., Blaine, J., Grant, B.F., Sartorius, N. 1997. WHO study on the reliability and validity of the alcohol and drug use disorder instruments: overview of methods and results. Drug Alcohol Depend. 47, 161-169.
Vega, W.A., Zimmerman, R.S., Warheit, G.J., Apospori, E., Gil, A.G. 1993. Risk factors for early adolescent drug use in four ethnic and racial groups. Am. J. Public Health 83, 185-189.

Weissman, M.M., Warner, V., Wickramaratne, P., Moreau, D., Olfson, M. 1997. Offspring of depressed parents: 10 years later. Arch. Gen. Psychiatry 54, 932-940.

Whitmore, E.A., Mikulich, S.K., Thompson, L.L., Riggs, P.D., Aarons, G.A., Crowley, T.J. 1997. Influences on adolescent substance dependence: Conduct disorder, depression, attention deficit disorder, and gender. Drug Alcohol Depend. 47, 87-97.

World Health Organization (WHO). 1992. The ICD-10 Classification of Mental and Behavioral Disorders: Clinical Descriptions and Diagnostic Guidelines. World Health Organization, Geneva, Switzerland.

World Health Organization (WHO). 1993. The ICD-10 Classification of Mental and Behavioral Disorders: Diagnostic Criteria for Research. World Health Organization, Geneva, Switzerland. 